\title{
Multi-professional audit supports clinical governance in projecting and implementing a new stroke care area
}

\author{
Marco Masina, ${ }^{1}$ Simona Malservisi, ${ }^{1}$ Elisabetta Domenichini, ${ }^{1}$ Pio Francesco Censoni, ${ }^{2}$ Nadia Mingolini ${ }^{2}$ \\ ${ }^{1}$ UOC Geriatria Bentivoglio; ${ }^{2}$ UO Medicina Riabilitativa Nord, Ospedale di Bentivoglio, AUSL di Bologna, Italy
}

\begin{abstract}
Patients with acute stroke have better outcomes in terms of survival or regaining independence if they receive organized inpatient care in a specific setting (Stroke Unit, SU) where a coordinated multidisciplinary team can ensure the best level of care. The clinical governance of an SU requires a systematic monitoring of diagnostic, clinical and therapeutic processes through a structured audit. The entire project and set up of a new SU in Bentivoglio, Italy, were based on a model that focused on multidisciplinary teamwork and clinical governance. An audit based on the Benjamin audit cycle followed every step of the set up of the new SU. Markers from national and international guidelines and from the Italian Regional Audit, together with a specific database were used. The audit showed a high level of care and a significant improvement in the majority of clinical, diagnostic and therapeutic parameters. Only a few markers (i.e. waiting times for ultrasound tomography and prescription of oral anticoagulation therapy) required specific projects in order to improve the results. Our experience confirmed that a structured audit can support clinical governance of an SU by monitoring clinical processes and quality of care. Such an audit involves the whole professional team and shows the effects of any single actions. It also helps integration and co-operation among staff. Furthermore, a structured audit is a useful instrument for professional accountability for both qualitative and quantitative aspects of care.
\end{abstract}

\section{Introduction}

The most recent systematic reviews of the literature have confirmed that providing professionals with information about their performance in the form of an audit improves quality standards of daily clinical practice and care..$^{1-3} \mathrm{It}$ is widely agreed that in caring for patients with acute stroke, if the evidence-based indications of the audit are followed, with regard to diagnosis, therapy, and

Correspondence: Marco Masina, UOC Geriatria Bentivoglio, Via Marconi 35, 40010, Bentivoglio (BO), Italy.

Tel. +39.51.6644394 - Fax: +39.51 .6644491 .

Mob. +39.339.3051053.

E-mail: marco.masina@ausl.bo.it

Key words: multi-professional audit, clinical governance, Stroke Care Area.

Conference presentation: GIMBE Award 2011. Abstract available from: Evidence 2012;4(1):e1000003.

Conflict of interests: the authors declare no potential conflict of interests.

This work is licensed under a Creative Commons Attribution NonCommercial 3.0 License (CC BY-NC 3.0).

CCopyright M. Masina et al., 2013

Licensee PAGEPress, Italy

Italian Journal of Medicine 2013; 7:56-63

doi:10.4081/itjm.2013.56 prevention of complications, both the disabling effects of the event and mortality are reduced. ${ }^{4}$ To guarantee the highest standards of care possible to acute stroke patients, clinical governance of the stroke care unit must be based on objective data provided by a systematic monitoring of diagnostic, clinical and therapeutic markers. This can be provided by a structured audit. ${ }^{5}$

In order to provide the best care for the acute stroke patient, the Metropolitan Stroke Network of the Province of Bologna (Rete Stroke Metropolitana della Provincia di Bologna) has set up a stroke unit at the Geriatric Department of the public healthcare hospital in Bentivoglio. ${ }^{6}$ The project began in 2008 and aimed to identify dedicated space and infrastructures, obtain the necessary equipment, and provide a traditional training program. This training program will include the organization and participation of geriatricians, nurses and physiotherapists in specialized courses and workshops at the hospital. Alongside traditional training, a clinical governance program has also been designed to include a structured audit of the new stroke care unit covering clinical, diagnostic, therapeutic and patient care. Continuous monitoring procedures have been implemented.

\section{Objectives}

The aims of the project were: i) to set up a stroke care unit at the public healthcare hospital of Bentivoglio, northern Italy, and train staff through a clinical governance program in order to verify performance and 
promote accountability; ii) to compare performance of the stroke care unit with that of the stroke unit (SU) at the main public healthcare hospital in Bologna, using common criteria as established by the guidelines of international agencies and of the Italian Stroke Prevention and Educational Awareness (SPREAD) project; ${ }^{7,8}$ iii) to evaluate the efficacy of reporting and audit on improving the quality of care of acute stroke patients, identifying and resolving the critical issues raised.

\section{Materials and Methods}

\section{The Stroke Care Project}

The Bentivoglio Stroke Care Project is based on the principles of a multi-professional and collaborative teamwork approach. ${ }^{9,10}$ A summary of the organizational model adopted is shown in Figure 1. This model consists in the initial involvement of a multi-

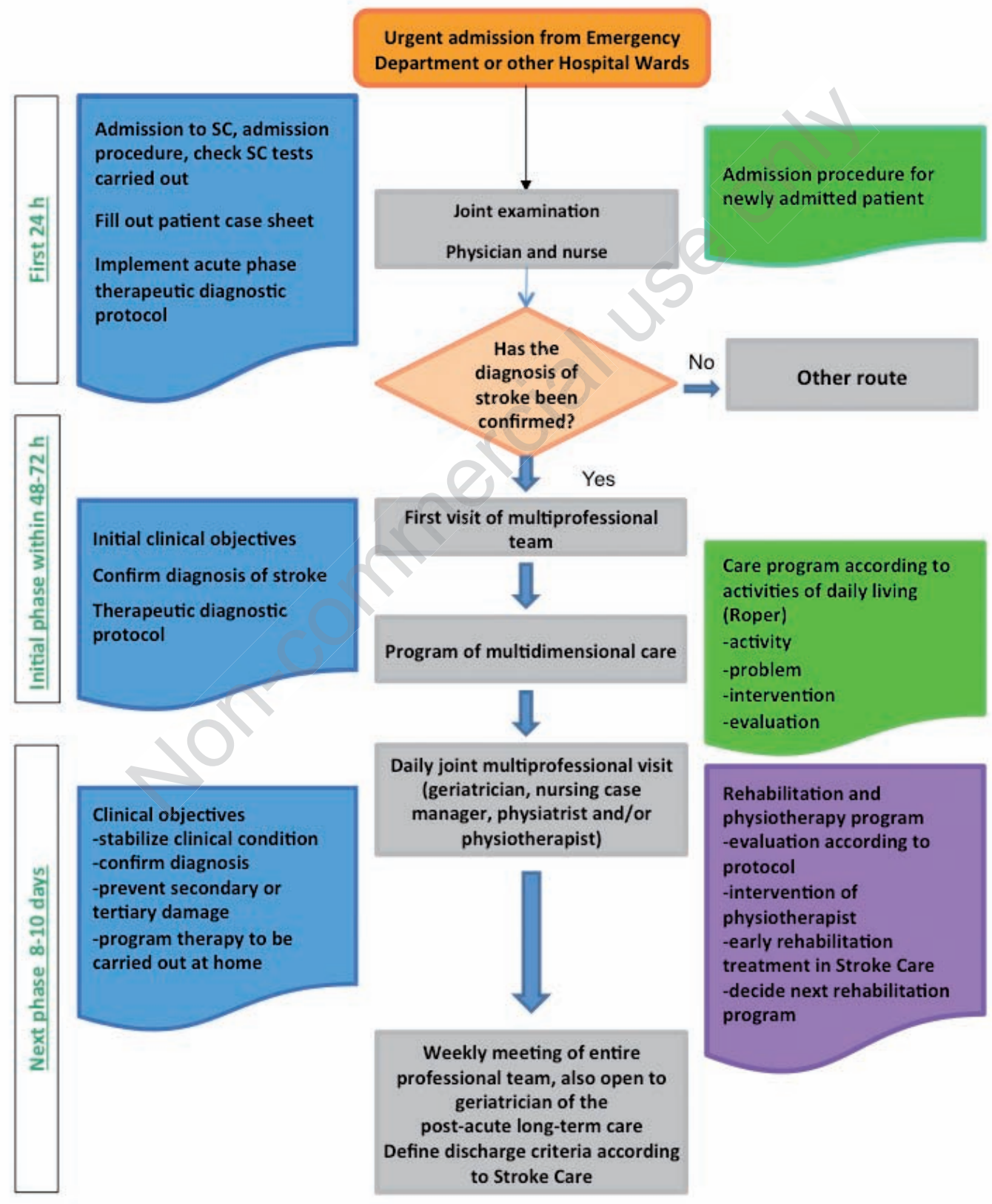

Figure 1. Flow chart of organizational model of multiprofessional and multidisciplinary care in the Bentivoglio Stroke Care Project. 
professional team made up of geriatricians, physiatrists, nursing care managers and physiotherapists. The team meets the morning after the patient has been admitted. Subsequent weekly meetings will be attended also by the physician and the nursing care manager responsible for post-acute long-term care to discuss and establish the discharge conditions (both ordinary and assisted) and/or the rehabilitation or long-term stay arrangements.

\section{Clinical governance}

The initial design of the Bentivoglio Stroke Care Unit included staff training, provision of appropriate space and infrastructure, and the necessary equipment. Since then, these aspects have been supplemented by the design and set up of a specific Stroke Audit structured according to the systematic model of Benjamin ${ }^{11}$ (Table 1).

The Stroke Audit covers six areas of clinical and general patient care and uses specific markers for each area (Table 2). The items and markers referring to care standards have formed the basis of stroke care in the hospitals involved. The Bentivoglio Stroke Care Project was designed according to national and international guidelines, such as those of the Italian Stroke Prevention and Educational Awareness (SPREAD 2007) project and the American Heart Association and American Stroke Association (AHA/ASA 2008). Regional documents and the Regional Stroke Audit were also consulted.

Table 1. Acute Stroke Care Project based on the Benjamin cycle.

\begin{tabular}{ll}
\hline Phase 1 & Preparation (2008) \\
\hline Phase 2 & $\begin{array}{l}\text { Selection of review criteria, definition of a minimum } \\
\text { standard, and presentation to the multi-professional } \\
\text { team (2008) }\end{array}$ \\
\hline Phase 3 & $\begin{array}{l}\text { Measure performance levels of the Geriatric Depart- } \\
\text { ment, of any differences in standards, and identifica- } \\
\text { tion of the various objectives according to professional } \\
\text { field (2009-2010) }\end{array}$ \\
\hline Phase 4 & $\begin{array}{l}\text { Report performance of the Stroke Care Unit in the 1 } \\
\text { 6 months of activity (May-November 2010) and com- } \\
\text { pare with reference standards }\end{array}$ \\
\hline Phase 5 & $\begin{array}{l}\text { Identify significant differences in standard markers, } \\
\text { discuss with team and establish strategies for improve- } \\
\text { ment }\end{array}$ \\
\hline $\begin{array}{l}\text { Re-Audit: aimed at those areas presenting the greatest } \\
\text { problems (phase 4) and for which specific strategies } \\
\text { for improvement and continuous monitoring were de- } \\
\text { veloped (phase 5) for some of the markers (phase 4) } \\
\text { as quality control. }\end{array}$ \\
\end{tabular}

Phases 3-5 of the Audit and phase 6 of the Re-Audit have been approved and included in the Hospital Training Program for the Bentivoglio public healthcare service (no. 7750/2009, 8742/2010, 10304/2011).
Data sources used were: the hospital admissions report (from the hospital discharge files), patient clinical case sheets and discharge papers. The indications of the report on the results of the Stroke Care pilot study (Rapporto sui risultati dello studio pilota stroke care $)^{12}$ and other public healthcare administrative applications formed the basis of the development of a specific database to be used by the entire hospital network (geriatricians, physiatrists and physiotherapists, and nursing staff). This database was used to collect and analyze data, and also allowed for continuous monitoring and periodic reassessment to be made.

An evaluation of the activity of the geriatric department included 53 patients admitted in the first six months of 2009. An analysis of the first six months of activity of the Bentivoglio Stroke Care Unit looked at the 84 patients admitted between May and October 2010. The Re-Audit considered the 78 patients admitted in the 6-month period from April to September 2011.

All multi-professional meetings (stages 3-5 of the Audit and stage 6 of the Re-Audit) were included in the Hospital Training Program (no. 7750/2009, 8742/2010, 10304/2011) in order to guarantee a continuous training program based on a comparison between the activities actually carried out and the recommendations established by the related guidelines. Table 3 shows how the different stages of project design and training both support each other and are integrated, and the specific corresponding stages of the Audit.

The entire project took almost four years to develop and received the 2011 GIMBE Award (Gruppo Italiano per la Medicina Basata sull'Evidenza, Italian Group for Evidence-Based Medicine) for a clinical governance project at the $6^{\text {th }}$ National GIMBE Congress in Bologna, northern Italy.

\section{Results}

Results for each individual evaluation field are shown in the middle columns of Table 2. Evaluation for the first six months of the Stroke Care Unit's activities relating to 84 patients admitted to the Bentivoglio Stroke Care Unit in 2010 show the expected improvement in parameters with respect to those in the geriatric department in 2009. High standards were achieved in almost all fields. This improvement confirms the positive effects of the training program on the quality of clinical patient care. Alongside this, the Audit showed and quantified two critical issues. The first was unexpected and involved the waiting time for an echoDoppler. The second was represented by the fact that prescription of oral anticoagulant therapy in patients with confirmed cardio-embolic stroke had improved but was still not optimal.

At the end of 2010, the performance standards of the first six months of the Bentivoglio Stroke Care Unit 
were also compared with those available in the 20072009 Regional Audit, the results of which had just become available. This Audit provided a benchmark between the clinical and patient care standards of the Bologna Stroke Unit and the care of patients with acute stroke in some other internal medicine and geriatric departments elsewhere in the province. In this way it was possible to verify the differences in some of the markers at the Bentivoglio Stroke Care Unit during the first six months of operations compared with the many years experience of a specialized hospital unit. The methods used to make this comparison did, however, have some limitations. The Regional Audit covered data from a sample of around 100 patients from over 400 admitted. The

Table 2. Markers and summary of results of phase 4 of the 2010 Audit and of the 2011 Re-Audit.

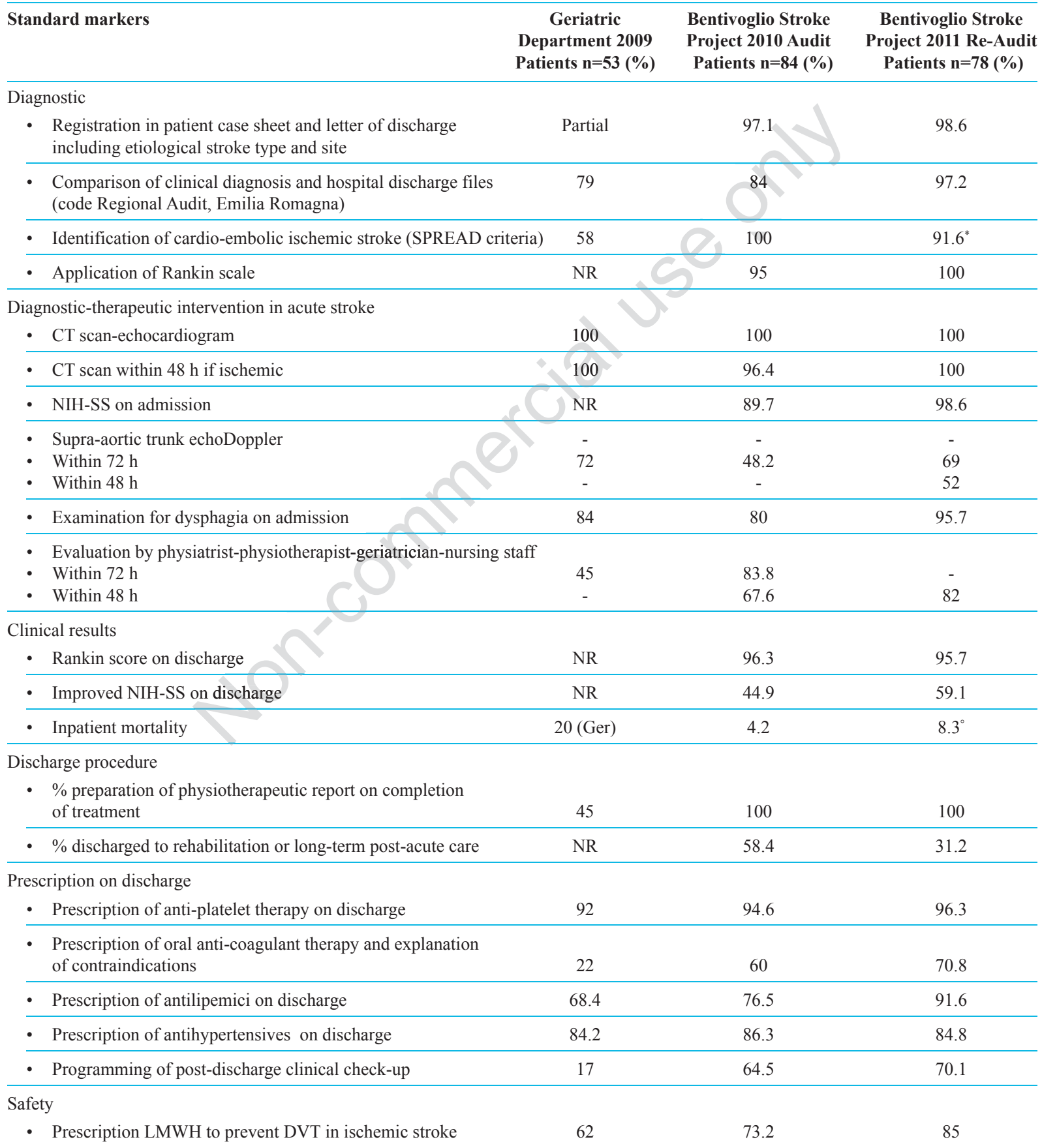

"Errors of overdiagnosis of cardio-embolism; 'values lower than those reported in literature (10-12\%). SPREAD, Stroke Prevention and Educational Awareness project; NR, not reported; CT, computerized tomography; NIH-SS, National Institutes of Health Stroke Scale; Ger, geriatric; LMWH, low-molecular-weight heparin; DVT, deep venous thrombosis. 
Table 3. Set up of the clinical governance project of Bentivoglio Acute Stroke Unit.

\section{8 - Hospital budget objective}

Draw up Bentivoglio Stroke Care Project according to multidisciplinary and multiprofessional model involving:

- Bentivoglio Geriatric Department + northern area of longterm care unit

- Northern Emergency Department

- Northern Rehabilitative Medicine and Extended Rehabilitation Unit

- Technical and rehabilitative care service (nursing staff /auxiliary nursing staff - physiotherapist) geriatric-rehabilitation departments

December 2008

Deliver project to the General Medicine Department

2009 Set up specific training programs for:

- Geriatricians: Training and refresher course in diagnosis and clinical treatment of acute stroke in the stroke unit by the Stroke Unit 'O. Maggiore' Hospital, Bologna

- Nursing/auxiliary nursing staff: interprofessional course in theory and practice Care of the stroke patient in the Northern Area also open to staff of the Northern Long-term Care Unit

- Physiatrists and physiotherapists: course in theory and practice specific to diagnosis and treatment of dysphagia

- Geriatrics: course in diagnostic supra-aortic trunk echoDoppler (2009) followed by hands on training

- Inclusion of clinical-diagnostic Audit on mangement of stroke patients in the Bentivoglio Geriatric Department training program (no. 7750/09)

January-June 2010

- All equipment obtained (monitors, electric adjustable beds, wheelchairs, etc.)

- Inclusion of clinical-diagnostic-therapeutic-patient care Audit on mangement of acute stroke patients in the Bentivoglio Stroke Unit training program (no. 8742/10)

17 May 2010

Set up phase 4 at the Bentivoglio Geriatric Stroke Care Unit, Nothern Metropolitan Stroke Network of the Province of Bologna:

- Implementation of Project clinical and care models

- Register action taken and markers used in special collective team database

- Implementation of continuous monitoring system (Bentivoglio Stroke Care Unit)
January-June 2008

Phase 1 - Preparation of Audit (identify needs)

Preliminary analysis (retrospective analysis of Geriatric Department patient case sheets 2007) of:

- Number and type of stroke admitted to Bentivoglio Geriatric Department

- Modality of management of acute stroke patient

- Diagnostic-therapeutic course and discharge

- Modality of drawing up letter of discharge of stroke patients

July-December 2008

Start phase 2 - Identification of reference guidelines: (SPREAD 5th ed. rev. 2007, AHA/ASA 2007) $)^{7,8}$

January-June 2009: Completion of phase 2

- Select for review and marker criteria (reference criteria Emilia Romagna of Regional Audit)

- Definition of minimum reference for Bentivoglio

- Present markers and standards to geriatric team

July-December 2009

Start phase 3 - Performance evaluation:

- Retrospective analysis of case sheets of stroke patients admitted to Geriatric Department and Long-Term Care Unit Jan-June 2009

- Identify differences in reference minimum standards

- Present results to geriatric team

January-June 2010: Expand phase 3 of Audit to include patient care:

- Identify minimum care standards nursing staff/auxiliary staffphysiotherapists

- Analysis of care parameters on case sheets Jan-June 2009

- Identify differences in reference minimum standards

- Present results to multi-professional team

July-December 2010

Phase 4 - Mid-Audit check:

- Analysis of differences to standards adopted for 1 st 6 months of activity

- Present analysis of $1^{\text {st }} 3$ months activity to Clinical Management Committee, Bologna Public Health Service

- Present results of phase 4 of Audit to multi-professional team (feedback)

January-June 2011

Phase 5 - Prepare Re-Audit:

- Complete report of Stroke Care Audit and present to the Hospital Clinical Management Committeee

- Present report to GIMBE National Congress (GIMBE Award 2011)

- Implementation of continuous monitoring system

- Team discussion of the significant differences in standards identified

- Establish strategies for improvement

- Participation of physicians, nursing staff and physiotherapists at training events and specialist congresses and meetings

- Participation in the ATA-AF study on prescription of anti-coagulant therapy in internal medicine and geriatric departments

- Inclusion of clinical-diagnostic-therapeutic-patient care Audit on mangement of acute stroke patients in the Bentivoglio Stroke Unit (feedback) in the 2011 Bentivoglio Hospital training program (no. 10304 /2011)
July-December 2011

Phase 6 Re-Audit (carrying out strategies for improvement):

- Analysis of markers of greatest problems identified in phase 4 and those in phase 5 for which specific strategies of improvement have been developed

- Monitoring of some significant markers of procedure quality

- Present results to team and complete report of Re-Audit for the Hospital Clinical Management Committeee

SPREAD, Stroke Prevention and Educational Awareness project; AHA/ASA, American Heart Association and American Stroke Association project; ATA-AF, Anti-Thrombotic Agents Atrial Fibrillation project; GIMBE, Gruppo Italiano per la Medicina Basata sull'Evidenza (Italian Group for Evidence-Based Medicine). 
Bentivoglio Audit, on the other hand, covered all 84 admissions in the 6-month period observed. Furthermore, the markers used were not exactly the same. Table 4 shows the values of the markers for which a direct comparison could be made. These confirm modest negative differences (correct use of the hospital discharge files, application of the National Institutes of Health Stroke Scale (NIH-SS) and the Rankin admission-discharge scale, prescription of oral anti-coagulant therapy in cases of cardio-embolism) and identify the areas of intervention. It is important also to report the positive differences; the quick intervention of the multi-professional team ( $84 \%$ within $72 \mathrm{~h} v s 67 \%)$ confirms the effectiveness of the organizational model adopted in Bentivoglio.

In 2011, the team set about to improve its services and, in particular, to deal with the critical issues that came up both in the benchmarking with the Regional Audit (correct use of the hospital discharge files and application of the NIH-SS and the Rankin admissiondischarge scale) and in the internal Audit (waiting times for echoDoppler and prescription of oral anticoagulant therapy).

As far as the correct use of the hospital discharge files and application of the NIH-SS and the Rankin admission-discharge scale are concerned, as well as a training session, changes were made to the patients' clinical case sheets and reminders were sent to physi- cians in the departments involved (Stroke Care Unit, post-acute long-term admissions, rehabilitation).

In order to deal with the waiting times for an echoDoppler, resources were unified in one pool and shared with the internal medicine department, and a training program was set up to allow another geriatrician to perform the examination (training courses and on-site tutors).

For the prescription of oral anti-coagulant therapy, steps were taken to promote a greater understanding of the need for such therapy. Staff also took part in the Anti-Thrombotic Agents Atrial Fibrillation (ATA-AF) project developed by the Italian National Association of Hospital Cardiologists and the Federation of Associations of Hospital Doctors on Internal Medicine (ANMCO-FADOI).

The programmed Re-Audit was carried out in 2011. This analyzed the 78 patients admitted in the 6-month period corresponding to that first evaluated in 2010 . There was a slight improvement in all markers, both in fields in which initial standards were already high and in those in which specific projects had subsequently been developed. Results are shown in Table 2. Markers relating to diagnostic standards, intervention in the acute phase, and to the prescription of therapy on discharge remained extremely high. There was a correlation between the differences in the markers relating to

Table 4. Comparison with markers of 2007-2009 Regional Audit.

\begin{tabular}{|c|c|c|}
\hline Standard markers & $\begin{array}{c}\text { 2007-09 Regional } \\
\text { Stroke Unit } \\
\text { Audit (\%) }\end{array}$ & $\begin{array}{l}2010 \text { Bentivoglio } \\
\text { Stroke Care Unit } \\
\text { Audit (\%) }\end{array}$ \\
\hline \multicolumn{3}{|l|}{ Diagnosis } \\
\hline - Compare clinical diagnosis and hospital discharge file (code Regional Audit, Emilia Romagna) & 100 & 84 \\
\hline - Application of Rankin scale on admission & 99.1 & 95 \\
\hline \multicolumn{3}{|l|}{ Diagnostic-therapeutic intervention in acute stroke } \\
\hline - CT scan within $24 \mathrm{~h}$ & 97.4 & 96.4 \\
\hline - NIH-SS on admission & 99.1 & 89.7 \\
\hline - Evaluation by physiatrist-physiotherapist-geriatrician-nursing staff within $72 \mathrm{~h}$ & 61 & 83.8 \\
\hline \multicolumn{3}{|l|}{ Clinical results } \\
\hline - Application of Rankin scale on discharge & 99 & 96.3 \\
\hline - Inpatient mortality & 12.6 & 4.2 \\
\hline \multicolumn{3}{|l|}{ Discharge procedure } \\
\hline - Standard discharge from Stroke Care Unit & 55.6 & 41.1 \\
\hline - Transfer for rehabilitation (inpatient rehabilitation + long-term post-acute care) & 42.3 & 58.5 \\
\hline \multicolumn{3}{|l|}{ Prescription on discharge } \\
\hline - Prescription of anti-platelet therapy on discharge & 83.5 & 94.6 \\
\hline $\begin{array}{l}\text { Prescription of oral anticoagulant therapy } \\
(+ \text { explanation of contraindications })\end{array}$ & $\begin{array}{c}47 \\
(94)\end{array}$ & 60 \\
\hline \multicolumn{3}{|l|}{ Safety } \\
\hline - Prescription LMWH to prevent DVT in ischemic stroke & 43 & 73.2 \\
\hline
\end{tabular}

CT, computerized tomography; NIH-SS, National Institutes of Health Stroke Scale; LMWH, low-molecular-weight heparin; DVT, deep venous thrombosis. 
clinical results, such as hospital mortality, improvement in the use of the NIH-SS on discharge and the choice of discharge arrangements, and these were strictly related to the case-mix. These cannot, therefore, be evaluated individually. There was an increase in mortality from $4.2 \%$ to $8.3 \%$; however, this was still lower than that reported in literature (approx. 10-12\%) and can be interpreted as a progressive use of the Stroke Care Unit to deal with more complex and demanding cases. The Re-Audit showed that less use was made of rehabilitation and long-term admission services; this is in line with the improvement seen in patient neurological profile on discharge (improved NIH-SS: $59.1 \%$ vs $44.9 \%$ ).

There was a significant improvement in the waiting time for echoDoppler $(70 \%$ carried out within $72 \mathrm{~h}$ and $50 \%$ within $48 \mathrm{~h}$ ) with respect to 2010 (48.9\% within $72 \mathrm{~h}$ ), but further improvements need to be made.

Prescription of oral anti-coagulant therapy in cases of cardio-embolism reached $70 \%$, but this also needs to be improved further. The incidence of pressure sores was slightly reduced.

There was a further positive improvement in waiting times before the intervention of the multi-professional team; $82 \%$ within $48 \mathrm{~h}$. This meant that care, clinical and physiotherapy programs could be speedily implemented in almost all patients, as set out by all the related guidelines.

\section{Limitations}

One of the limitations of this experience was the problem of data management, also because of the introduction of the changes to admission procedures made in 2010. Some data monitored in the Audit are still not available automatically and this means that departmental staff must register them separately on a special database.

Further limitations involve the data used in the comparison of standards with those reported in the Regional Audit of 2007-2009 that evaluated a sample of 110 patients, that is approximately $25 \%$ of patients admitted for acute stroke in the central stroke unit in 2007, and in which not all markers corresponded.

For the Bentivoglio Audit, an attempt was made to overcome any possible errors due to the sample used by always considering all patients admitted in the 6month observation period. However, it should be remembered that since less than 100 patients were involved, the difference of even just one patient can signify statistical differences of $1-2 \%$.

\section{Conclusions}

The Bentivoglio Stroke Care Audit represents a process of clinical governance developed at the Ben- tivoglio geriatric department alongside the creation of a Stroke Care Unit and staff training.

The Audit monitored some areas in which important improvements to the project had to be made regarding staff performance on levels of clinical intervention, diagnosis, therapy and patient care. Given the indications provided by literature and available guidelines, and following the experience of the Regional Audit, specific markers were identified, the differences seen in the hospital where the Stroke Unit was to be set up were measured, and objectives for improvement were established. Any improvement was evaluated during the first 6-month period of the Stroke Unit's operations in 2010. An improvement in most of the markers was seen compared with results for 2009 and, where comparisons could be made, these reached the same level as standards registered in the Regional Audit for the Stroke Unit of the main Bologna 'O. Maggiore' hospital.

There were few areas of non-conformity and specific projects to improve these were carried out. These were evaluated in the Re-Audit carried out in the second half of 2011, and while slight improvements were seen, the need to continue monitoring was underlined.

One of the areas in which the Audit approach has obtained the best results is seen in the English National Stroke Audit program. ${ }^{1}$ In its turn, the Emilia Romagna region of northern Italy has decided to promote clinical governance of stroke care by using a specific hospital and regional Audit. The experience with our Audit has shown how such a tool can be designed and implemented by an individual hospital department and how far it is capable of providing useful support in the difficult phase of setting up a new care service.

Adoption of the clinical Audit and being involved in its design allows us to integrate organizational decisions with evaluation strategies such that markers of quality can be monitored, progressive improvements in performance can be followed, problems can be identified and solutions found.

The Audit provides efficient support to the clinical governance of the Stroke Care Unit, monitoring the adoption of correct clinical and care procedures and strategies, and evaluating the quality of care provided for patients with acute stroke.

The Audit involves all the members of the multiprofessional team, providing prompt feedback on the significance and consequences of the diagnostic, therapeutic and care strategies adopted for each individual patient, and promoting collaboration and teamwork between staff.

Finally, the structured Audit is a useful approach to quantitative and qualitative accountability of the activities carried out both for patients themselves and for the public healthcare management. 


\section{References}

1. Jamtvedt G, Young JM, Kristoffersen DT, et al. Audit and feedback: effect on professional practice and health care outcomes. Cochr Database Syst Rev 2006;(2): CD000259.

2. Hysong SJ. Meta-analysis: audit and feedback features impact effectiveness on care quality. Med Care 2009; 47:356-63.

3. Cinotti R, Cartabellotta A. Progettare, realizzare, verificare un audit clinico. Bologna: Agenzia Regionale Emilia-Romagna; 2000. [In Italian]. Available from: http://www.regione.emilia-romagna.it/agenziasan/aree/ accred/accreditamento/sussidi/sussidio6.pdf

4. Stroke Unit Trialists' Collaboration. Organised inpatient (stroke unit) care for stroke (Cochrane Review). In: The Cochrane Library, Issue 4. Chichester, UK: John Wiley \& Sons, Ltd.; 2004.

5. Rudd AG, Hoffman A, Irwin P, et al. Stroke units: research and reality. Results from the National Sentinel Audit of Stroke. Qual Saf Health Care 2005;14:7-12.

6. Gruppo di Lavoro Regionale "Stroke Care". Documento di indirizzo per l'organizzazione dell'assistenza integrata al paziente con ictus - Programma Stroke Care DGR no. 1720 del 16/11/2007. Bologna: Assessorato Politiche per la Salute Regione Emilia-Romagna; 2007. [In Italian]. Available from: http://www.saluter.it/docu- mentazione/leggi/regionali/delibere/programmazioneprovvedimenti-regionali-del-2007/dgr-1720-2007

7. Goldstein LB, Bushnell CD, Adams Rj, et al. Guidelines for the primary prevention of stroke. A guideline for healthcare professionals from the American Heart Association/American Stroke Association. Stroke 2010;42: 517-84.

8. SPREAD (Stroke Prevention and Educational Awareness Diffusion). Ictus cerebrale: linee guida italiane di prevenzione e trattamento: $\mathrm{V}$ edizione stesura 16 febbraio 2007 e IV edizione stesura 7 gennaio 2010. [In Italian]. Available from: http://www.spread.it

9. Govan L, Weir CJ, Langhorne P. Organized inpatient (Stroke Unit) care for stroke. Stroke 2008;39:2402-3.

10. Stroke Unit Trialists' Collaboration. Organised inpatient (stroke unit) care for stroke. Cochr Database Syst Rev 2007;(4):CD000197.

11. Benjamin A. Audit: how to do it in practice. BMJ 2008; 336:1241.

12. Terni G, Accetta G, Biggeri A, et al. Rapporto sui risultati dello studio pilota "stroke care": Progetto di ricerca finalizzata 2004 ex art. 12 e 12 bis del Dlgs 502/92 come modificato e integrato dal dlgs 229/99 - Come garantire l'applicazione degli interventi efficaci nell'assistenza allo stroke. Bologna: Assessorato Politiche per la Salute Regione Emilia-Romagna; 2004. [In Italian]. Available from: http://asr.regione.emilia-romagna.it/wcm/asr/ric inn/prier_1/gr_v/pr_cerebro/stpr_ictus/pubblicazioni/ studio_multicentrico/link/risultati/analisi_risultati.pdf 